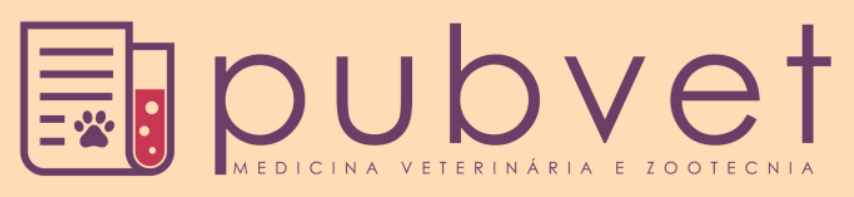

https://doi.org/10.22256/pubvet.v12n5a99.1-11

\title{
Aspectos da resposta imune em ovinos experimentalmente co- infectados com Corynebacterium pseudotuberculosis e Haemonchus
} contortus

\author{
Gabriele Rodrigues ${ }^{\ominus}$, Vera Lúcia Costa Vale ${ }^{\ominus}$, Alessandro Bitencourt Nascimento ${ }^{\ominus}$, \\ Aloisio Bitencourt Nascimento ${ }^{\ominus}$, Marcos da Costa Silva ${ }^{\ominus}$ 3, José Tadeu Raynal ${ }^{\ominus 1}$, Lilia \\ Ferreira de Moura $\operatorname{Costa}^{\ominus 1}$, Soraya Castro Trindade ${ }^{\ominus} 4$, Roberto Meyer ${ }^{\ominus}{ }^{*}$ \\ ${ }^{I}$ Departamento de Biointeração do Instituto de Ciências da Saúde da Universidade Federal da Bahia \\ ${ }^{2}$ Departamento de Ciências Exatas e da Terra, Universidade do Estado da Bahia \\ ${ }^{3}$ Departamento de Ciência da Vidas, Universidade do Estado da Bahia \\ ${ }^{4}$ Departamento de Saúde, Universidade de Feira de Santana \\ *Endereço dos autores para correspondência, Laboratório de Imunologia e Biologia Molecular, Instituto de Ciências da \\ Saúde, Universidade Federal da Bahia. Avenida Reitor. Miguel Calmon, S/N, Vale do Canela, Salvador, Bahia, Brazil. CEP: \\ 40.110-100. Phone: 55-71-3332-3341.Fax: 55-71-3235-9682. E-mail: rmeyer@ufba.br; (R. Meyer)
}

\begin{abstract}
RESUMO. O presente trabalho teve como objetivo avaliar a possível regulação negativa induzida por mecanismos Th2, desencadeados pelo helminto Haemonchus contortus, sobre a resposta por células do perfil Th1, importante para conter a infecção pelo cocobacilo Corynebacterium pseudotuberculosis, na infecção ovina concomitante por estes dois parasitas. Para tanto, avaliou-se a resposta Th1 em duas diferentes condições de infecção experimental, utilizando-se como indicador a produção in vitro de interferon- $\gamma$, que é a citocina mais típica do seu perfil, a partir de culturas de células do sangue periférico de ovinos co-infectados com estes dois parasitas, comparando-se com a sua produção, nas mesmas condições, em animais apenas infectados com a referida bactéria e usando-se como estímulo dois preparados antigênicos com diferentes graus de pureza. Os resultados evidenciaram uma tendência de redução na produção desta citocina nos animais coinfectados em relação àqueles infectados apenas com Corynebacterium pseudotuberculosis, nos dois protocolos experimentais. Quanto à resposta por anticorpos da classe $\operatorname{IgG}$ específicos contra esta bactéria, avaliada pelo teste imunoenimático ELISA e por western blot, não se observou diferenças entre os grupos infectados apenas com o bacilo ou com a dupla infecção.
\end{abstract}

Palavras chave: co-infecção, linfadenite, Haemonchus contortus

\section{Aspects of the immune response in sheep experimentally co-infected with Corynebacterium pseudotuberculosis and Haemonchus contortus}

ABSTRACT. The present work aimed to evaluate the possible negative regulation induced
by Th2 mechanisms, unleashed by the helminth Haemonchus contortus, on the response
by cells of the Th1 profile, important to contain the Corynebacterium pseudotuberculosis
cocobacillus infection, in the concomitant ovine infection by these two parasites. For this,
the Th1 response was evaluated in two different experimental infection conditions, using
the in vitro production of interferon, which is the most typical cytokine of its profile, from
cultures of peripheral blood cells of ovine animals co-infected with these two parasites,
compared to their production, under the same conditions, in animals only infected with the
said bacterium and using as stimulus two antigen preparations with different degrees of 
purity. The results evidenced a tendency of reduction in the production of this cytokine in the co-infected animals in relation to those infected with Corynebacterium pseudotuberculosis alone, in the two experimental protocols. As for the response by $\operatorname{IgG}$ class specific antibodies against this bacterium, evaluated by ELISA and western blot, no differences were observed between groups infected only with bacillus or with double infection.

Keywords: co-infection, Lymphadenitis, Haemonchus contortus

\title{
Aspectos de la respuesta inmune en ovinos experimentalmente coinfectados con Corynebacterium pseudotuberculosis $\boldsymbol{y}$ Haemonchus contortus
}

\begin{abstract}
RESUMEN. El presente trabajo tuvo como objetivo evaluar la posible regulación negativa inducida por mecanismos Th2, desencadenados por el helminto Haemonchus contortus, sobre la respuesta por células del perfil Th1, importante para contener la infección por el cocobacilo Corynebacterium pseudotuberculosis, en la infección ovina concomitante por estos dos parásitos. Para ello, se evaluó la respuesta Th1 en dos diferentes condiciones de infección experimental, utilizando como indicador la producción in vitro de interferón- $\gamma$, que es la citocina más típica de su perfil, a partir de cultivos de células de sangre periférica de ovinos coinfectados con estos dos parásitos, comparándose con su producción, en las mismas condiciones, en animales sólo infectados con la referida bacteria y usando como estímulo dos preparados antigénicos con diferentes grados de pureza. Los resultados evidenciaron una tendencia de reducción en la producción de esta citocina en los animales coinfectados en relación a aquellos infectados sólo con Corynebacterium pseudotuberculosis, en los dos protocolos experimentales. En cuanto a la respuesta por anticuerpos de la clase IgG específicos contra esta bacteria, evaluada por la prueba inmunoenimática ELISA y por Western blot, no se observaron diferencias entre los grupos infectados sólo con el bacilo o con la doble infección.
\end{abstract}

Palabras clave: co-infección, linfadenitis, Haemonchus contortus

\section{Introdução}

A linfadenite caseosa é uma doença infectocontagiosa crônica causada por um cocobacilo Gram+, Corynebacterium pseudotuberculosis, que acomete principalmente pequenos ruminantes. Apresenta alta prevalência em diversas regiões do Brasil, como demonstrado através de estudos soro-epidemiológicos (Meyer et al. 2005; Guimarães et al. 2011). Embora nestes animais a resposta por anticorpos seja intensamente dirigida contra a fosfolipase $\mathrm{D}$, uma exotoxina hemolítica e importante fator de virulência deste microrganismo (Jolly 1965; Brown et al. 1987), por se tratar de uma bactéria intracelular facultativa, a resposta imune celular é, sem dúvida, essencial para conter a infecção no interior de macrófagos (Gilleard 2013). Haemonchus contortus é um helminto hematófago do estômago de ruminantes, de distribuição mundial e altamente prevalente em rebanhos ovinos criados extensivamente também em várias regiões do Brasil (Gilleard 2013). Este verme induz a produção de citocinas Th2, como as interleucinas 4, 5 e 13 (Gill et al. 2000; AlbaHurtado \& Muñoz-Guzmán 2012), além de uma forte resposta por anticorpos, com degranulação de mastócitos e citotoxicidade por eosinófilos dependentes da IgE, especialmente na mucosa do abomaso, nicho do parasitismo por este verme (Meeusen \& Balic 2000).

Com base nas altas prevalências e da coexistência entre o helminto Haemonchus contortus e a bactéria Corynebacterium pseudotuberculosis nos rebanhos ovinos e caprinos em várias regiões do mundo, incluindo algumas regiões brasileiras, especialmente as criações do semiárido nordestino (Alencar et al. 2010), e levando-se em conta a já mencionada resposta Th2 montada pelo verme e a importância de mecanismos Th1 para a defesa contra esta bactéria, no presente trabalho buscou-se avaliar esta resposta em ovinos co-infectados por estes parasitas, utilizando-se como indicador a produção in vitro de interferon- $\gamma$, a partir de culturas de sangue periférico, usando-se como 
estímulo dois preparados antigênicos com diferentes graus de pureza.

\section{Material e Métodos}

\section{Animais}

Os ovinos utilizados nos experimentos foram animais sem raça definida (SRD), com idade entre três meses e seis meses de idade, ambos os sexos, com sorologia negativa para Corynebacterium pseudotuberculosis e livres ou infectados naturalmente com Haemonchus contortus. Os grupos foram mantidos nas condições de criação intensiva, na unidade experimental do Laboratório de Imunologia, em Salinas da Margarida, Bahia, Brasil.

\section{Grupos experimentais}

Os animais foram agrupados e submetidos a dois distintos delineamentos experimentais, conforme a descrição seguinte:

Experimento I, realizado com três grupos. O grupo controle $(\mathrm{Ct})$, foi composto por três animais livres de Haemonchus contortus e de Corynebacterium pseudotuberculosis; o grupo $\mathrm{Cp}$ infectado por Corynebacterium pseudotuberculosis no dia 0, por via subcutânea, na região pré-escapular direita, com $10^{7} \mathrm{CFU}$, composto por cinco animais; e o grupo de co-infecção $(\mathrm{Cp} \times \mathrm{Hc})$, com cinco animais previamente infectados com Haemonchus contortus e infectados com Corynebacterium pseudotuberculosis no dia zero. Neste experimento o acompanhamento da resposta imune ocorreu nos dias $0,15,30,60,90$, com coletas de sangue para cultura com estímulo com o antígeno Q5 para avaliar a produção in vitro de interferon- $\gamma$ e para avaliação da produção de anticorpos IgG específicos contra Corynebacterium pseudotuberculosis por ELISA indireto e, coletas de fezes para determinação de OPG e coprocultura.

No experimento II utilizou-se três grupos com cinco animais: grupo $\mathrm{Hc}$, composto por animais infectados com Haemonchus contortus, livres de Corynebacterium pseudotuberculosis; o grupo CpxHc, com ovinos co-infectados com Haemonchus contortus e Corynebacterium pseudotuberculosis no dia zero; e o grupo $\mathrm{Cp}$, com ovinos apenas infectados com Corynebacterium pseudotuberculosis no dia zero.

A inoculação de Corynebacterium pseudotuberculosis foi realizada através da via subcutânea, na região pré-escapular direita, numa dose de $4,4 \times 10^{7}$ CFU. A infecção com Haemonchus contortus foi realizada por via oral utilizando as larvas infectantes (L3), de acordo com o proposto por Muñoz-Guzmán et al. (2006). E o acompanhamento da resposta imune ocorreu nos dias $0,15,30,60,90,120,150,180$ e 240 , com coletas mensais de sangue para: cultura de sangue total com estímulo com o antígeno TPP, para a dosagem in vitro de IFN- $\gamma$, para avaliação dos níveis séricos de anticorpos IgG específicos contra Corynebacterium pseudotuberculosis por ELISA indireto e por western blot e, para a coleta de fezes para OPG e coprocultura.

\section{Obtenção de bactérias e antígenos}

Em ambos os experimentos se utilizou linhagem selvagem de Corynebacterium pseudotuberculosis para as infecções e a linhagem atenuada o preparo dos antígenos, ambas provenientes da Coleção de Microrganismos do Laboratório de Microbiologia do Instituto de Ciências da Saúde da UFBA. Foram semeadas em meio de infusão de cérebro e coração (BHI) e a seguir cultivadas a $37^{\circ} \mathrm{C}$, por 48 horas. Para a inoculação, após centrifugação e lavagem ajustouse para a quantidade de CFU a ser inoculada; para o teste imune enzimático (ELISA) utilizou-se o sobrenadante destas culturas (antígeno BHI) obtido conforme Carminati et al (2003); para a estimulação das culturas de sangue do primeiro experimento utilizou-se a fração antigênica Q5, obtida segundo Rodrigues (2009); finalmente, para a estimulação das culturas do segundo experimento e para o western blot usou-se a fração antigênica TPP (Paule et al. 2004).

\section{Avaliação da produção in vitro de interferon- $\gamma$}

Foi realizada a partir do sobrenadante de culturas de sangue total, mantidas por 48 horas, segundo Rebouças e colaboradores (2011). Como já mencionado, para o experimento I utilizou-se como estímulo a fração antigênica Q5 e no experimento II a fração TPP.

Avaliação da produção de anticorpos da classe IgG específicos para Corynebacterium pseudotuberculosis

Os níveis séricos de $\operatorname{IgG}$ foram determinados pelo ensaio imune enzimático (ELISA) e o reconhecimento de frações antigênicas foi realizado através de western blot, ambos procedimentos segundo o protocolo de Rebouças et al. (2013). 
Contagem de ovos por grama de fezes e cultivo de larvas

Para a contagem de ovos por grama de fezes (OPG) de nematódeos gastrintestinais, utilizou-se a técnica de Gordon e Whitlock, modificada por este último (Whitlock 1948). A coprocultura e a contagem de larvas foi realizada pela técnica de Ueno (1998).

\section{Análise estatística}

Como as variáveis estudadas não apresentaram distribuição normal, optou-se pela utilização de testes estatísticos de distribuição livre ou testes não paramétricos por não dependerem do conhecimento da distribuição da variável na população. Todas as análises dos dados obtidos foram feitas com o programa SPSS (Statistical Package for Social Sciences), versão 12.0 para Windows.

\section{Questões éticas}

Este trabalho foi aprovado pelo CEUA Comitê de Ética no Uso Animal do Instituto de Ciências da Saúde (ICS/UFBA), sob protocolo $n^{o}$ $071 / 2014$.

\section{Resultados}

\section{Experimento I}

Produção in vitro de interferon- $\gamma$ em cultura de sangue total frente ao estímulo antigênico Q5

A Figura 1 apresenta os resultados obtidos com a produção in vitro de interferon- $\gamma$ em culturas de sangue total de ovelhas, no tempo $0,15,30,60 \mathrm{e}$ 90 dias, nos três grupos experimentais.

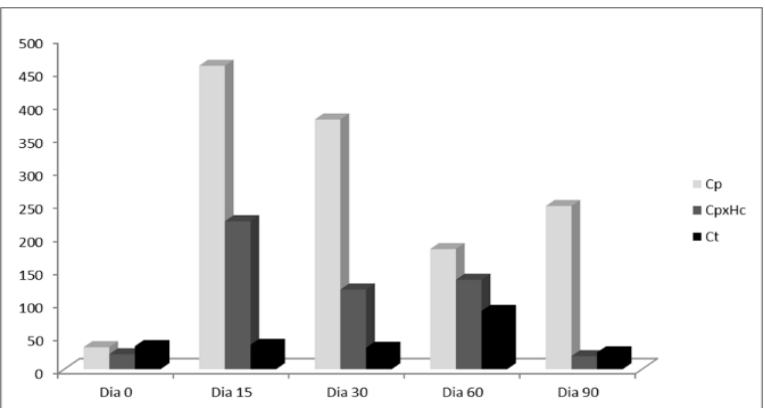

Figura 1. Produção in vitro de interferon-gama $(\mathrm{pg} / \mathrm{mL})$ por células do sangue periférico após estímulo com 40ug de da fração Q5 por ovinos dos três grupos experimentais. Grupo $\mathrm{Cp}(\mathrm{n}=5)$ : Animais infectados com Corynebacterium pseudotuberculosis; Grupo $\mathrm{Cp}$ x $\mathrm{Hc}(\mathrm{n}=5)$ : Animais coinfectados com Corynebacterium pseudotuberculosis e Haemonchus contortus (naturalmente infectados) e Grupo controle ( $n=3)$ : Animais inoculados com solução salina $0,9 \%$.
Observa-se que no tempo zero a dosagem foi basal para todos os grupos. O grupo dos animais infectados com C. pseudotuberculosis apresentou uma maior expressão desta citocina quando comparado com o grupo de co-infecção em todos os tempos pós-infecção, entretanto sem diferença estatisticamente significante.

Nos tempos de 30 e 60 dias de infecção o grupo de co-infecção apresentou maior expressão desta citocina quando comparada ao tempo zero ( $\mathrm{P}<$ $0,05)$. O grupo representado pelos animais coinfectados apresentou uma queda estatisticamente significante aos 90 dias de infecção quando comprados aos 30 dias de infecção $(\mathrm{P}<0,05)$. Redução semelhante observou-se no mesmo grupo no tempo 90 dias quando comparada ao tempo de 60 dias de infecção $(\mathrm{P}<0,05)$. Com 30 dias observou-se também diferença estatisticamente significante entre todos os grupos experimentais, mantendo o padrão de expressão observado a partir dos 15 dias de infecção, com expressão aumentada de IFN- $\gamma$ no grupo infectado com $C$. pseudotuberculosis ao se comparar com o grupo de co-infecção $(\mathrm{P}<0,05)$. Ambos os grupos experimentais apresentaram maior produção da referida citocina em relação ao grupo controle $(\mathrm{P}<0,05)$.

Utilizou-se o mitógeno pokeweed (PWM) como controle de reatividade das culturas, obtendo-se sempre valores desta citocina acima de $1000 \mathrm{pg} / \mathrm{mL}$.

Produção de IgG total pelos ovinos ao longo da infecção

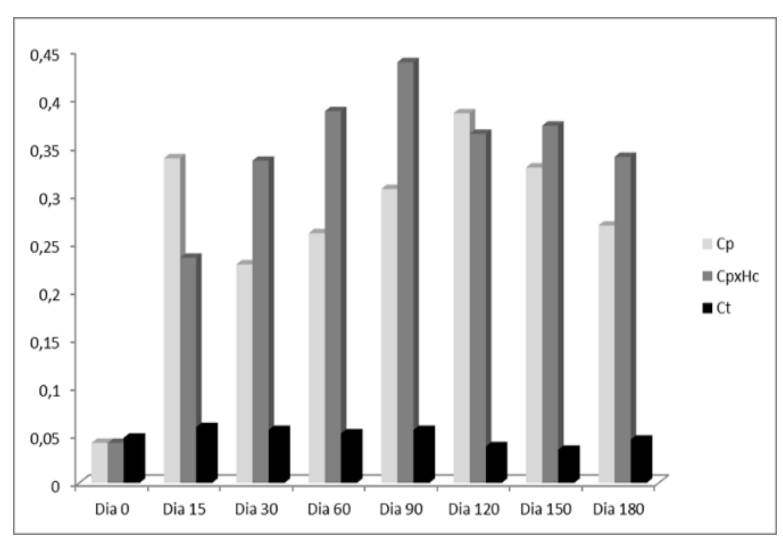

Figura 2. Cinética da produção de IgG total específica antiCorynebcterium pseudotuberculosis em ovinos ao longo de 90 dias. Grupo $\mathrm{Cp}(\mathrm{n}=5)$ : Infectados com Corynebcterium pseudotuberculosis; Grupo $\mathrm{Cp}$ x Hc ( $\mathrm{n}=5)$ : Co-infectados com Corynebcterium pseudotuberculosis e Haemonchus contortus (infecção natural) e Grupo $\mathrm{Ct}(\mathrm{n}=3)$ : Controle inoculado com solução salina $0,9 \%$. ELISA Indireto sensibilizado com antígeno BHI. Ponto de corte utilizado foi 0,150 D.O. 
Ao se analisar a produção de $\operatorname{IgG}$ ao longo do tempo, observa-se que não existe diferença estatística entre os grupos no tempo zero e que o grupo controle apresentou níveis basais durante os 180 dias de infecção.

Os dois grupos experimentais apresentaram produção expressiva de IgG antiCorynebacterium, mas sem diferença estatística entre eles em todos os tempos. Nos dias 30, 60, 90, $120, \quad 150$ e 180 constatou-se diferenças estatisticamente significantes quando comparados os grupos controle e infectado com Corynebacterium pseudotuberculosis $(\mathrm{P}<0,01)$. Ao comparar o grupo de co-infecção com o grupo controle houve diferença aos $60(\mathrm{P}<0,01)$, 90, 120 e $150(\mathrm{P}<0,05)$ dias de infecção. No tempo de 60 dias observou-se diferença estatisticamente significante entre todos os grupos $(\mathrm{P}<0,01)$.

Foi observado na análise entre os tempos, diferença estatisticamente significante no grupo $\mathrm{Cp}$, em todos os pontos pós-inoculação em relação ao tempo zero, sendo $15,30,150$ e 180 dias $(\mathrm{P}<$ $0,05)$ e 360,90 e 120 dias $(\mathrm{P}<0,01)$. No grupo de co-infecção essa diferença só ocorreu entre o doa zero e o dia $60(\mathrm{P}<0,05)$.

\section{Acompanhamento da infecção pelo Haemonchus contortus}

A Figura 3 apresenta os resultados da contagem de ovos liberados nas fezes dos animais dos grupos Controle e Co-infecção.

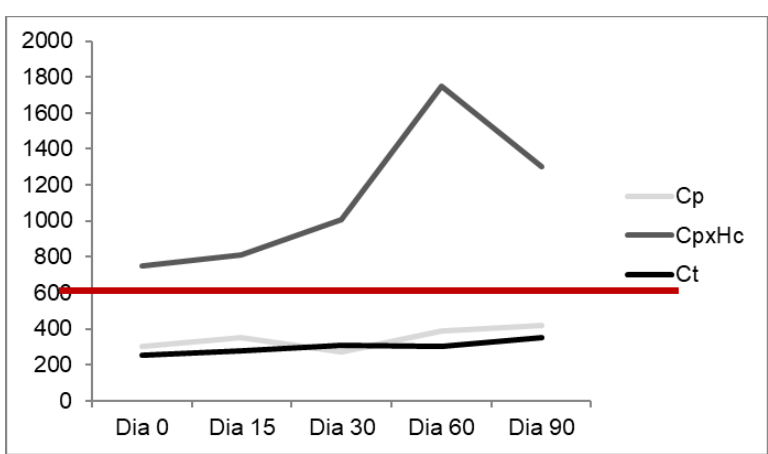

Figura 3. Medianas dos valores de OPG nos animais dos grupos $\mathrm{Cp}$, CpxHc e $\mathrm{Ct}$, ao longo de 90 dias de infecção (ponto de corte $=700$ ).

Levando-se em conta o ponto de corte de 700 ovos por grama de fezes, o grupo co-infecção já apresentou valores superiores (medianas) a este limite no dia 15. Conforme pode ser constatado na figura 4 , no tempo zero todos os grupos apresentaram níveis baixos, como era esperado. A partir do dia 15 os grupos $\mathrm{Cp}$ e $\mathrm{CpxHc}$ apresentaram grande aumento na expressão de interferon- $\gamma$ quando comparados ao tempo zero $(\mathrm{P}$ $<0,01)$.

\section{Experimento II}

Produção in vitro de interferon- $\gamma$ em cultura de sangue total frente ao estímulo antigênico TPP

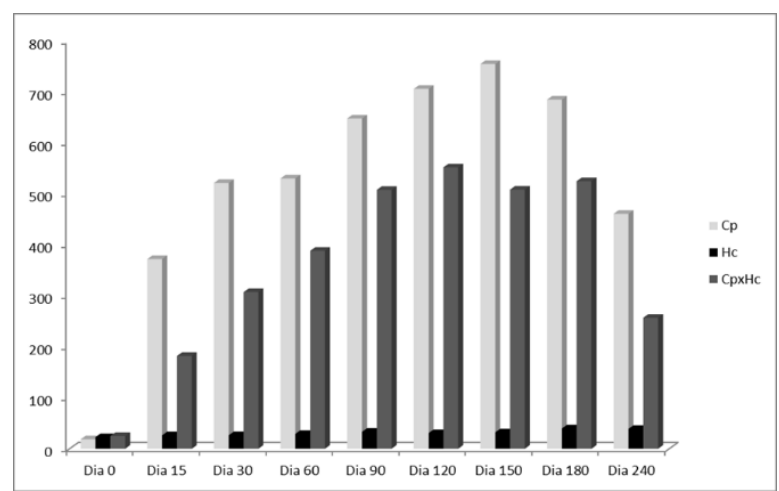

Figura 4. Produção in vitro de interferon-gama por células do sangue periférico após estímulo com 40ug de da fração TPP. Grupo Cp $(\mathrm{n}=5)$ : Animais infectados com Corynebacterium pseudotuberculosis, Grupo $\mathrm{Cp}$ x $\mathrm{Hc}(\mathrm{n}=5)$ : Animais coinfectados com Corynebacterium pseudotuberculosis e Haemonchus contortus e Grupo $\mathrm{Hc} \quad(\mathrm{n}=5)$ : Animais infectados com Haemonchus contortus.

Os valores de interferon- $\gamma$ contabilizados para os animais do grupo infectado com Corynebacterium pseudotuberculosis nos tempos de 60, 90, 120, 150 e 180 dias foram superiores àqueles verificados aos 15 dias $(\mathrm{P}<0,01)$. A partir do dia 180 esta produção declina. Enquanto crescente, apresentou diferenças estatísticas quando se comparou $90(\mathrm{P}<0,05), 120,150$ e 180 dias $(\mathrm{P}<0,01)$ com 60 dias pós-inóculo.

Aos 90 dias de infecção, a produção desta citocina foi significativamente mais elevada que $15,30(\mathrm{P}<0,01)$ e 60 dias $(\mathrm{P}<0,05)$. O pico observado aos 150 dias foi superior a produção correspondente a 90 dias de infecção $(\mathrm{P}<0,05)$ e o oposto foi visto com a diminuição significativa aos 240 dias quando comparado ao tempo de 90 $\operatorname{dias}(\mathrm{P}<0,01)$.

A produção da citocina em estudo nos tempos de 120,150 e 180 dias foi superior aos tempos anteriores de 15, 30, 60 dias, bem como ao último tempo experimental $(\mathrm{P}<0,01)$.

Em todos os pontos experimentais pósinfecção, os animais infectados com $C$. pseudotuberculosis apresentaram maior expressão desta citocina em relação aos animais coinfectados $(\mathrm{P}<0,01), 90$ dias $(\mathrm{P}<0,05)$. 
O grupo Hc, livre de Corynebacterium pseudotuberculosis, se manteve em níveis basais ao longo de todo experimento.

Os valores referentes aos controles negativos, que não receberam estímulo e aos controles positivos, estimulados com o mitógeno PWM funcionaram a contento, garantindo a qualidade das culturas de sangue periférico. No entanto não foram incluídos nos gráficos, pois títulos discrepantes comprometeriam a interpretação clara dos dados.

\section{Produção de IgG total ao longo da infecção}

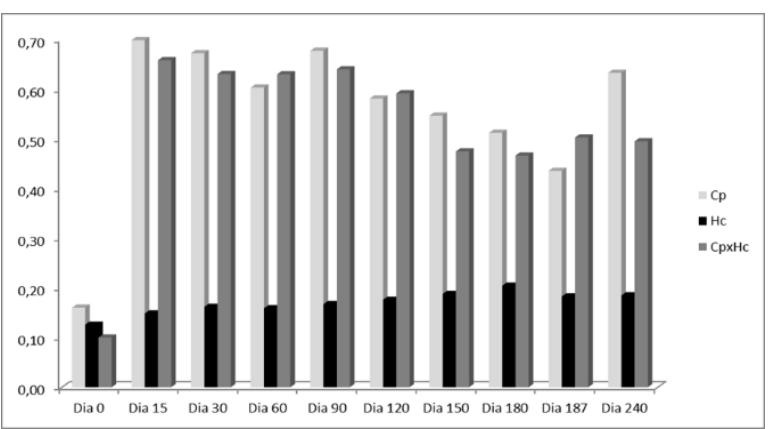

Figura 5. Cinética da produção de IgG total específica antiC. pseudotuberculosis em ovinos ao longo de 240 dias de observação. Grupo $\mathrm{Cp}(\mathrm{n}=5)$ : Infectados com Corynebacterium pseudotuberculosis; Grupo $\mathrm{Hc}(\mathrm{n}=5)$ : Infectados com Haemonchus contortus; Grupo Cp x Hc (n = 5): Co-infectados com Corynebacterium pseudotuberculosis e Haemonchus contortus. ELISA Indireto usando antígeno BHI.

Os valores de densidade ópticas no dia zero se apresentaram baixos no tempo zero, aumentando expressivamente aos 15 dias de infecção para os grupos infectados com C. pseudotuberculosis e co-infectados, até o fim do experimento.

Os grupos Cp e CpxHc apresentaram produção de IgG muito similares em todos os tempos experimentais. Mas, ambos os grupos apresentaram diferenças estatisticamente significativa quando comparados com o grupo $\mathrm{Hc}$, em todos os tempos pós-inoculação.

$\mathrm{Na}$ comparação entre os tempos, só houve diferença no grupo infectado com Corynebacterium pseudotuberculosis (Cp) aos 15, 30 e 90 dias em relação ao tempo zero.

\section{Reconhecimento antigênico através de western blot}

A figura 6 ilustra os achados quanto ao reconhecimento de frações antigênicas a partir de pool dos soros de cada um dos grupos ( $\mathrm{Cp}$ e CpxHc), obtidos nos dias 0, 30, 90 e 180 por representarem, pelo teste ELISA, momentos ainda sem resposta (dia 0) com resposta alta (dias 30 e 90) e em declínio. Apesar de numerosas bandas terem sido fracamente reveladas, foi possível observar-se o reconhecimento de uma banda com peso molecular em torno de $30 \mathrm{kDa}$ no trigésimo dia, e duas outras bandas de cerca de 72 e $120 \mathrm{kDa}$ nos dias 90 e 180. Com exceção da ausência de imunorreatividade para a banda de $120 \mathrm{kDa}$ aos 180 dias, não foram observadas outras diferenças entre os dois grupos.

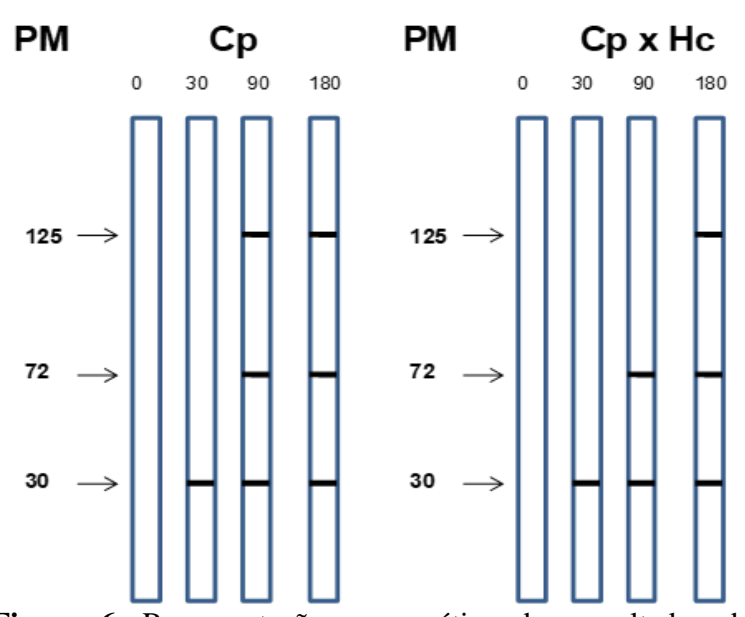

Figura 6. Representação esquemática dos resultados do western blot realizado com pool de soros dos animais dos grupos Cp e Cp x Hc, nos dias 0, 30, 90 e 180.

\section{Discussão}

A importância do IFN- $\gamma$ na resposta imune celular contra Corynebacterium pseudotuberculosis já foi anteriormente descrita (Lan et al. 1999; Pepin et al. 1999). Em um estudo utilizando a dosagem de IFN- $\gamma$ como um possível marcador para o diagnóstico da linfadenite caseosa em caprinos e ovinos, observou-se também associação entre altos níveis desta citocina em animais com granulomas (Rebouças et al. 2011). Dentre as principais ações do INF- $\gamma$ destaca-se a ativação de macrófagos e a indução da expressão de moléculas apresentadoras de antígenos - MHC de classe I e II, sendo a sua produção estimulada principalmente pela IL-12. Esta citocina tem papel decisivo no controle de infecções por microrganismos intracelulares (Perry et al. 1997; Schoenborn \& Wilson 2007; Brandão et al. 2011). Assim, embora não se tenha dúvida de que a resposta por anticorpos seja de grande importância para a neutralização do principal fator de virulência desta bactéria, a sua fosfolipase D (Dorella et al. 2006), mecanismos que venham a reduzir ou inibir a resposta imune Th1contra este microrganismo, certamente permitirão a evolução desfavorável desta doença para o hospedeiro. 


\section{Avaliação da reatividade in vitro de células do sangue periférico}

Paule et al. (2003) mostraram a produção de IFN- $\gamma$ em caprinos utilizando antígenos secretados. Logan et al. (2005) (2005) demonstraram em bovinos infectados com $M$. bovis, que altas concentrações de IFN- $\gamma$ indicam momentos ou períodos deproliferação do microrganismo.

Resultados preliminares mostraram que células dos camundongos infectados com a linhagem selvagem VD57, sob a ação dos estímulos antigênicos em estudo, apresentaram um pico com 15 dias de infecção para as citocinas TNF- $\alpha$, IFN$\gamma$, IL-10 e IL-4, decrescendo aos 35 dias. Nos animais deste grupo, os antígenos secretados, total e fracionado, apresentaram resultados muito semelhantes quanto ao padrão e quantidade de citocinas produzidas "in vitro", havendo diferenças estatisticamente significantes somente nos níveis de TNF- $\alpha$ e IL-4 produzidos, sendo que a fração Q5 induziu maior produção de ambas as citocinas. Este grupo experimental desenvolveu a doença, com formação de granulomas, perda de peso e alto índice de mortalidade. Está forte resposta inflamatória inicial observada nesses camundongos foi evidenciada pela elevada produção de TNF- $\alpha$, sob a ação dos dois estímulos (Rodrigues 2015).

No presente trabalho, o antígeno Q5 induziu maior expressão de IFN- $\gamma$ nos animais inoculados apenas com Corynebacterium pseudotuberculosis quando comparado aos animais co-infectados em todos os tempos pós-infecção sugerindo uma modulação da resposta imune pelo $H$. contortus. Apesar desta diferença estar nitidamente evidente (Figura 1), diferença estatisticamente significante só foi observada aos 30 dias de infecção, provavelmente devido ao desvio padrão nestes grupos, nos demais tempos experimentais.

Esta variabilidade de resposta por IFN- $\gamma$ é observada nos animais experimentais em cada ponto de coleta e ao longo do período experimental. Conforme os trabalhos de Prescott et al. (2002), bem como de Sunil et al. (2008), quanto aos valores de IFN- $\gamma$ produzido in vitro por células sanguíneas, alguns animais elevam seus valores enquanto que outros decrescem os valores em um mesmo ponto de coleta; em nossos experimentos, além de ocorrerem discrepâncias entre os valores de diferentes animais inoculados num mesmo dia e com a mesma dose bacteriana, as flutuações ocorreram também ao longo da própria cinética de resposta de cada indivíduo. Segundo estes autores, estas flutuações ocorreriam devido a fatores como a fase da doença, severidade da infecção, grau de disseminação bacteriana no organismo, ao status de saúde do animal, bem como a heterogeneidade genética. Em nossos experimentos utilizou-se animais sem raça definida, com diferentes padrões fenotípicos (embora com predomínio de fenótipo Santa Inês, considerada raça resistente a este helminto), certamente incluindo animais com maior ou menor resistência ao Haemonchus contortus, o que deve ter se constituído num fator de variabilidade de resposta por esta citocina. Estas variações também são observadas quando se acompanha a cinética dos níveis plasmáticos desta citocina (Sacchini et al. 2012).

Ao analisar a produção da citocina estudada diante do estímulo do antígeno TPP, a modulação imune foi evidenciada em todos os tempos pósinoculação, com diferenças estatísticas robustas, no grupo de co-infecção.

$\mathrm{O}$ antígeno TPP revelou altos níveis de interferon-gamma, especialmente no grupo $\mathrm{Cp}$, confirmando os achados de Rebouças et al. (2011) que verificaram altos índices de produção de IFN$\gamma$ pela indução do antígeno secretado TPP, bem como os resultados de Meyer et al. (2005), que constataram alta produção desta citocina pelo estímulo com antígenos secretados e baixa produção quando os leucócitos foram estimulados com antígeno somático.

A produção de interferon-gamma foi evidenciada precocemente, aos 15 dias após a infecção. Trabalhos anteriores indicam que níveis significantemente elevados desta citocina já podem ser detectados a partir de 35 dias após a infecção (Prescott et al. 2002; Sunil et al. 2008). Contudo, estes trabalhos, ambos do mesmo grupo de pesquisa canadense, utilizaram a dose de $4 \times 10^{7}$ células de $C$. pseudotuberculosis para a infecção experimental, além de utilizarem estímulos antigênicos baseados em lisados bacterianos (50 $\mu \mathrm{g})$ e células bacterianas inativadas $\left(1,5 \times 10^{7}\right.$ células) para induzir a resposta celular in vitro. Possivelmente, as diferenças de resultados podem estar associadas às diferenças de protocolos experimentais.

Os níveis elevados de IFN- $\gamma$ sob estímulo de TPP se mantiveram crescentes até os 180 de infecção, e após este tempo mesmo com decréscimo, apresentou produção expressiva. Já a fração Q5, apresentou produção mais discreta e 
com queda mais precoce, ainda que o acompanhamento tenha ocorrido apenas até os 90 dias. Considerando que a estimulação com os antígenos secretados foram realizados em experimentos distintos, sendo indivíduos e doses de infecção diferentes, não foi possível comparar o efeito indutor da resposta celular pelas ferramentas da estatística.

Considerando que animais geneticamente resistentes à infecção por este helminto apresentam uma resposta imune do tipo Th2 intensa, podendo atuar sinergicamente com os anticorpos, assim contribuindo para expressão da imunidade adquirida no hospedeiro (Gill et al. $\underline{2000}$ ), os achados no presente trabalho, apesar da já mencionada limitação pelo tamanho da amostra e da variabilidade genética dos animais estudados, sugerem que esta resposta imune predominantemente Th2 esteja envolvida na modulação negativa na produção de IFN $\gamma$. Adicionalmente a esta imunidade humoral intensa, caracterizada pela formação de anticorpos das classes IgG, IgM, IgA e IgE, sendo essa última de grande importância na defesa anti-helmíntica, observa-se também mecanismos de imunidade celular que certamente também contribuem na resistência contra este helminto (Molento 2004). Embora a resposta anti-helmíntica não tenha sido avaliada neste trabalho, fica claro que tal resposta pode ser montada, tendo em vista os mensuráveis níveis de IFN- $\gamma$ observados nos grupos de coinfecção.

Baseado em todas as evidências revisadas neste estudo, pode-se entender que o efeito imunomodulador induzido pela presença do parasita, pode ser uma das explicações para o aumento da mortalidade nos pequenos ruminantes co-infectados, considerando que além da alteração do perfil imunológico Th1 predominante protetor para o animal, existe a própria debilidade do animal quando acometido por ambas enfermidades.

\section{A produção de anticorpos ao longo da imunização}

A imunidade humoral também é importante no combate a Corynebacterium pseudotuberculosis, pois possivelmente dentre outras moléculas, a sua exotoxina, que pode ser neutralizada por anticorpos, é decisivaa para a sua disseminação no hospedeiro (Batey 1986). Entretanto, é importante destacar que embora a produção de anticorpos seja decisiva para evitar a disseminação da bactéria no organismo hospedeiro, a presença, sobretudo no microambiente do granuloma, de citocinas como
IFN- $\gamma$ pode limitar a doença e reduzir a disseminação deste microrganismo (Pepin et al. 1999). Por outro lado, de acordo com este autor, a fosfolipase D certamente não participa dos eventos iniciais que levam à formação do granuloma, mas parece ser importante dentro dele, para a persistência crônica destas lesões. O acompanhamento da cinética da produção de IgG anti-Corynebacterium pseudotuberculosis observada no experimento I mostrou que os níveis expressivos deste anticorpo nos grupos Cp e de coinfecção em relação ao tempo zero. A heterogeneidade genética entre indivíduos do mesmo grupo, já discutida anteriormente, certamente explica que o grupo composto por animais co-infectados só tenha apresentado diferença estatisticamente significativa no tempo de 60 dias, quando comparado ao tempo zero $(\mathrm{P}<$ $0,01)$.

No entanto, o grupo $\mathrm{Cp}$ x $\mathrm{Hc}$ apesar de apresentar maiores valores de densidade ótica quando comparados ao grupo $\mathrm{Cp}$, não mostrou diferença estatística nesta análise. Nos dias 60, 90, 120, 150 e 180 a produção deste anticorpo específico foi significativamente maior para os dois grupos inoculados, quando comparados ao grupo controle. De maneira semelhante a cinética de IgG ocorreu no experimento II, com um pico na produção aos 15 dias pós infecção, decrescendo discretamente aos 120 dias. Ainda assim, a expressão desta imunoglobulina se manteve elevada ao longo de todo o acompanhamento. Em todos os pontos analisados houve diferença entre os grupos de Cp e CpxHc em relação ao grupo $\mathrm{Hc}$. No entanto entre os dois grupos infectados com Corynebacterium pseudotuberculosis, não se observou diferenças mensuráveis entre eles, resultados estes semelhantes aos encontrados no primeiro experimento.

Os valores elevados para as densidades óticas de IgG, constatados no segundo experimento, estão de acordo com os achados encontrados por Cerqueira (2016), que estudando a resposta humoral em caprinos infectados com diferentes linhagens de $C$. pseudotuberculosis pelas diferentes testes ELISA indiretos, observou que a infecção com linhagem atenuada ou selvagem induzia resposta humoral elevada quando comparadas pelo ELISA utilizando o antígeno TPP obtido de uma linhagem atenuada. Em contrapartida, quando os mencionados resultados obtidos no segundo experimento foram comparados com a fração Q5, observou-se o desenvolvimento de um perfil de resposta bem 
superior, talvez por se tratar de um antígeno mais puro quando comparado com o TPP que é um secretado total. Apesar do ELISA com antígeno purificado diferenciar os animais infectados com as diferentes linhagens bacterianas (Cerqueira 2016), o ELISA com antígeno BHI também apresentou expressiva capacidade de discriminar os grupos compostos por animais infectados, corroborando com os resultados obtidos por Carminati (2005). As diferenças de resultados verificadas entre esses autores se devem, provavelmente, às diferentes concentrações e linhagens bacterianas utilizadas na infecção.

Tais resultados são coerentes com a relação estabelecida entre Corynebacterium pseudotuberculosis e o seu hospedeiro, pois apesar do padrão intracelular de proliferação (Pascual et al. 1995), produtos secretados por este microrganismo, como a exotoxina, são essenciais para o sucesso do parasitismo, cuja neutralização é feita especialmente por anticorpos (Zaki 1976). Estes achados também têm sido descritos na infecção por outros microrganismos onde mecanismos celulares e humorais são importantes para conter o processo patológico (Diniz et al. 2004).

\section{Conclusões}

Corynebacterium pseudotuberculosis induz no hospedeiro ovino expressivas respostas imunes dos perfis Th1 e Th2 que podem ser detectadas utilizando-se antígenos secretados por estes microrganismos e preparados com diferentes graus de pureza (BHI, Q5 e TPP). Os antígenos Q5 e TPP se mostraram eficientes em detectar a produção in vitro da citocina interferon- $\gamma$ e os níveis de síntese desta citocina foram utilizados como indicadores dos mecanismos mediados por células (Th1). A comparação da referida produção in vitro desta citocina entre animais infectados apenas com Corynebacterium pseudotuberculosis com aqueles co-infectados com este microrganismo e o com o helminto Haemonchus contortus, evidenciou valores mais baixos nestes últimos animais, sugerindo regulação negativa exercida pelo verme, o que é concordante com aqueles de diversas outras publicações que atribuem à hierestimulação do perfil Th2 por este parasita a responsabilidade sobre este fenômeno. Este fenômeno pode explicar altas prevalências da infecção por Corynebacterium pseudotuberculosis em regiões onde a infecção por este microrganismo ocorre concomitantemente com a infecção por este nematódeo. A resposta através de anticorpos avaliada pelo teste imunoenzimático ELISA se mostrou discretamente mais intensa nos animais infectados apenas com a bactéria, embora este aumento não tenha tido significado estatístico.

\section{Referências bibliográficas}

Alba-Hurtado F. \& Muñoz-Guzmán M.A. 2012. Immune responses associated with resistance to haemonchosis in sheep. BioMed research international 2013, 1-11.

Alencar S.P., Mota R.A., Coelho M.C.O.C., Nascimento S.A., Oliveira Abreu S.R. \& Castro R.S. 2010. Perfil sanitário dos rebanhos caprinos e ovinos no sertão de pernambucano. Ciência Animal Brasileira 11, 131-40.

Batey R.G. 1986. Frequency and consequence of caseous lymphadenitis in sheep and lambs slaughtered at a Western Australian abattoir. American journal of veterinary research 47, 482-5.

Brandão A.P., Oliveira F.S., Carvalho N.B., Vieira L.Q., Azevedo V., Macedo G.C. \& Oliveira S.C. 2011. Host susceptibility to Brucella abortus infection is more pronounced in IFN- $\gamma$ knockout than IL-12/ß2microglobulin double-deficient mice. Clinical and Developmental Immunology 2012, 1-7.

Brown C.C., Olander H.J. \& Alves S.F. 1987. Synergistic hemolysis-inhibition titers associated with caseous lymphadenitis in a slaughterhouse survey of goats and sheep in Northeastern Brazil. Canadian Journal of Veterinary Research 51, 46-9.

Carminati, R. Bahia, R., Costa, L. F. D. M., Paule, B. J. A., Vera, L. V., Regis, L., Freire, S. M., Nascimento, I. N., Schaer, R. \& Meyer, R. 2003. Determinação da sensibilidade e da especificidade de um teste ELISA indireto para o diagnóstico de linfadenite caseosa em caprinos, Revista Ciências Médicas Biológicas 2, 88-93.

Cerqueira R.B.A.. 2016. Avaliação da resposta humoral de caprinos infectados com duas linhagens de Corynebacterium pseudotuberculosis através de diferentes testes ELISA Indiretos. In: Instituto de Ciências da Saúde. Universidade Federal da Bahia., Salvador, Bahia.

Diniz S.N., Reis B.S., Goes T.S., Zouain C.S., Leite M.F. \& Goes A.M. 2004. Protective immunity induced in mice by F0 and FII 
antigens purified from Paracoccidioides brasiliensis. Vaccine 22, 485-92.

Dorella F.A., Pacheco L.G.C., Oliveira S.C., Miyoshi A. \& Azevedo V. 2006. Corynebacterium pseudotuberculosis: microbiology, biochemical properties, pathogenesis and molecular studies of virulence. Veterinary research 37, 201-18.

Gill H.S., Altmann K., Cross M.L. \& Husband A.J. 2000. Induction of T helper 1-and T helper 2-type immune responses duringHaemonchus contortus infection in sheep. Immunology 99, 458-63.

Gilleard J.S. 2013. Haemonchus contortus as a paradigm and model to study anthelmintic drug resistance. Parasitology 140, 1506-22.

Guimarães A.S., Carmo F.B., Heinemann M.B., Portela R.W.D., Meyer R., Lage A.P., Seyffert N., Miyoshi A., Azevedo V. \& Gouveia A.M.G. 2011. High sero-prevalence of caseous lymphadenitis identified in slaughterhouse samples as a consequence of deficiencies in sheep farm management in the state of Minas Gerais, Brazil. BMC veterinary research 7, 68 .

Jolly R.D. 1965. The pathogenic action of the exotoxin of Corynebacterium ovis. Journal of comparative pathology 75, 417-31.

Lan D.T.B., Makino S., Shirahata T., Yamada M. \& Nakane A. 1999. Tumor necrosis factor alpha and gamma interferon are required for the development of protective immunity to secondary Corynebacterium pseudotuberculosis infection in mice. Journal of Veterinary Medical Science 61, 1203-8.

Logan K.E., Chambers M.A., Hewinson R.G. \& Hogarth P.J. 2005. Frequency of IFN- $\gamma$ producing cells correlates with adjuvant enhancement of bacille Calmette-Guèrin induced protection against Mycobacterium bovis. Vaccine 23, 5526-32.

Meeusen E.N.T. \& Balic A. 2000. Do eosinophils have a role in the killing of helminth parasites? Parasitology today 16, 95-101.

Meyer R., Regis L., Vale V., Paule B., Carminati R., Bahia R., Moura-Costa L., Schaer R., Nascimento I. \& Freire S. 2005. In vitro IFNgamma production by goat blood cells after stimulation with somatic and secreted Corynebacterium pseudotuberculosis antigens. Veterinary immunology and immunopathology 107, 249-54.
Molento M.B. 2004. Resistência de helmintos em ovinos e caprinos. Revista Brasileira de Parasitologia 13, 82-6.

Muñoz-Guzmán M.A., Cuéllar-Ordaz J.A., Valdivia-Anda A.G., Buendía-Jiménez J.A. \& Alba-Hurtado F. 2006. Correlation of parasitological and immunological parameters in sheep with high and low resistance to haemonchosis. Canadian Journal of Animal Science 86, 363-71.

Pascual C., Lawson P.A., Farrow J.A.E., Gimenez M.N. \& Collins M.D. 1995. Phylogenetic analysis of the genus Corynebacterium based on $16 \mathrm{~S}$ rRNA gene sequences. International journal of systematic and evolutionary microbiology 45, 724-8.

Paule B.J.A., Azevedo V., Regis L.F., Carminati R., Bahia C.R., Vale V.L.C., Moura-Costa L.F., Freire S.M., Nascimento I. \& Schaer R. 2003. Experimental Corynebacterium pseudotuberculosis primary infection in goats: kinetics of $\mathrm{IgG}$ and interferon- $\gamma$ production, IgG avidity and antigen recognition by Western blotting. Veterinary immunology and immunopathology 96, 129-39.

Paule B.J.A., Meyer R., Moura-Costa L.F., Bahia R.C., Carminati R., Regis L.F., Vale V.L.C., Freire S.M., Nascimento I. \& Schaer R. 2004. Three-phase partitioning as an efficient method for extraction/concentration of immunoreactive excreted-secreted proteins of Corynebacterium pseudotuberculosis. Protein expression and purification 34, 311-6.

Pepin M., Sanchis R. \& Paton M. 1999. La lymphadénite caséeuse des ovins et des caprins. Point vétérinaire 30, 33-40.

Perry L.L., Feilzer K. \& Caldwell H.D. 1997. Immunity to Chlamydia trachomatis is mediated by $\mathrm{T}$ helper 1 cells through IFNgamma-dependent and-independent pathways. The Journal of Immunology 158, 3344-52.

Prescott J.F., Menzies P.I. \& Hwang Y.-T. 2002. An interferon-gamma assay for diagnosis of Corynebacterium pseudotuberculosis infection in adult sheep from a research flock. Veterinary microbiology 88, 287-97.

Rebouças M.F., Loureiro D., Bastos B.L., MouraCosta L.F., Hanna S.A., Azevedo V., Meyer R. \& Portela R.W. 2013. Development of an indirect ELISA to detect Corynebacterium pseudotuberculosis specific antibodies in sheep employing T1 strain culture supernatant 
as antigen. Pesquisa Veterinária Brasileira 33, 1296-302.

Rebouças M.F., Portela R.W., Lima D.D., Loureiro D., Bastos B.L., Moura-Costa L.F., Vale V.L., Miyoshi A., Azevedo V. \& Meyer R. 2011. Corynebacterium pseudotuberculosis secreted antigen-induced specific gammainterferon production by peripheral blood leukocytes: potential diagnostic marker for caseous lymphadenitis in sheep and goats. Journal of veterinary diagnostic investigation 23, 213-20.

Rodrigues G.C. 2015. Papel de antígenos secretados de uma linhagem atenuada de Corynebacterium pseudotuberculosis na indução de resposta imune em camundongos. In: Programa de Pós-Graduação em Imunologia. Universidade Federal da Bahia, Salvador, Bahia.

Sacchini F., Luciani M., Salini R., Scacchia M., Pini A., Lelli R., Naessens J., Poole J. \& Jores J. 2012. Plasma levels of TNF- $\alpha$, IFN- $\gamma$, IL-4 and IL-10 during a course of experimental contagious bovine pleuropneumonia. BMC veterinary research 8,44 .

Schoenborn J.R. \& Wilson C.B. 2007. Regulation of interferon- $\gamma$ during innate and adaptive immune responses. Advances in immunology 96, 41-101.
Sunil V., Menzies P.I., Shewen P.E. \& Prescott J.F. 2008. Performance of a whole blood interferon-gamma assay for detection and eradication of caseous lymphadenitis in sheep. Veterinary microbiology 128, 288-97.

Ueno H. 1998. Manual para diagnóstico das helmintoses de ruminantes. UFRGS, JICA, Porto Alegre.

Whitlock H.V. 1948. Some modifications of the McMaster helminth egg-counting technique and apparatus. Journal of the Council for Scientific and Industrial Research. Australia 21, 177-80.

Zaki M.M. 1976. Relation between the toxogenicity and pyogenicity of Corynebacterium ovis in experimentally infected mice. Research in veterinary science 20, 197-200.

Article History:

Received 28 February 2018

Accepted 6 March 2018

Available online 3 May 2018

License information: This is an open-access article distributed under the terms of the Creative Commons Attribution License 4.0, which permits unrestricted use, distribution, and reproduction in any medium, provided the original work is properly cited. 